\title{
ADOLESCÊNCIA E POLÍTICA PÚBLICA: A PRÁTICA PSICANALÍTICA EM ABRIGO INSTITUCIONAL
}

\author{
Arthur Cardoso Chicralla ${ }^{1}$ \\ Universidade do Estado do Rio de Janeiro, Brasil \\ a chicralla@yahoo.com.br \\ ORCID: 0000-0002-0385-2204 \\ Heloisa Caldas ${ }^{2}$ \\ Universidade do Estado do Rio de Janeiro, Brasil \\ helocaldasr@gmail.com \\ ORCID: 0000-0001-6264-1223
}

DOI: 10.17533/udea.affs.v16n31a01

\section{Resumo}

Este artigo apresenta uma leitura psicanalítica sobre a prática em uma instituição de acolhimento para adolescentes em situação de ameaça ou violação de direitos. Abordaremos, inicialmente, alguns aspectos das políticas públicas no Brasil com relação aos adolescentes. Em seguida, vamos nos valer da forma como a psi- canálise pensa a adolescência para, ao final, ilustrar a possibilidade de prática da psicanálise com jovens em um abrigo institucional, conforme definido pelas Orientações técnicas (CNAS \&amp; CONANDA, 2009), cujo objetivo é acolher adolescentes em situação de violação de direitos com vínculos familiares rompidos

1 Psicólogo e psicanalista. Especialista em Clínica Psicanalítica pela Universidade Federal do Rio de Janeiro (IPUB/UFRJ). Mestre em Psicanálise e Políticas Públicas pela Universidade do Estado do Rio de Janeiro (PGPSA/UERJ).

2 Docente e atual Coordenadora do Programa de Pós-Graduação da Universidade do Estado do Rio de Janeiro (PGPSA/IP/UERJ); AME da Escola Brasileira de Psicanálise - EBP e da Associação Mundial de Psicanálise - AMP. 
ou fragilizados, visando à reintegração familiar ou à colocação em família substituta. $\mathrm{O}$ acolhimento institucional propiciado a essa clientela resulta de uma medida judicial de caráter excepcional e deve durar o menor tempo possível; além disso, possui como propósito assegurar os direitos previstos em lei a crianças e adolescentes.

Palavras chave: Abrigo institucional; adolescência; políticas públicas; Psicanálise.

\section{ADOLESCENCIA Y POLÍTICA PÚBLICA: LA PRÁCTICA PSICOANALÍTICA EN AMPARO INSTITUCIONAL}

\section{Resumen}

Este artículo presenta una lectura psicoanalítica sobre la práctica en una institución de acogida para adolescentes en situación de amenaza o violación de derechos. Abordaremos, inicialmente, algunos aspectos de las políticas públicas en Brasil en relación con los adolescentes. Luego, nos serviremos de la forma como el psicoanálisis piensa la adolescencia para, al final, ilustrar la posibilidad de práctica del psicoanálisis con jóvenes en un amparo institucional, según lo definido por las Orientaciones técnicas (CNAS \&amp; CONANDA, 2009), cuyo objetivo es acoger adolescentes en situación de violación de derechos con vínculos familiares rotos o debilitados, con el propósito de una reintegración familiar o de ubicación en una familia sustituta. La acogida institucional propiciada a esta población resulta de una medida judicial de carácter excepcional y debe durar el menor tiempo posible; además, tiene como propósito asegurar a niños y adolescentes los derechos previstos en ley.

Palabras clave: amparo institucional, adolescencia, políticas públicas, psicoanálisis. 


\title{
ADOLESCENCE AND PUBLIC POLICY: PSYCHOANALYTIC PRACTICE UNDER INSTITUTIONAL PROTECTION
}

\begin{abstract}
This paper presents a psychoanalytic reading of the practice in an institution for adolescents who have been threatened or whose rights have been violated. We will approach, initially, some aspects of the public policies in Brazil in relation to adolescents. Then, we will use the way psychoanalysis thinks adolescence to, finally, illustrate the possibility of practice of psychoanalysis with young people under institutional protection, as defined by the Technical Orientations (CNAS \&amp; CONANDA, 2009) which aim at taking care of adolescents whose
\end{abstract} rights have been violated and their family bonds broken or weakened, in order to enable a family reintegration or to locate them in a foster family. The institutional care provided to this population is the result of a legal action of exceptional character and it should last as short time as possible. Additionally, it aims at protecting the rights established by law for children and adolescents.

Keywords: institutional protection, adolescence, public policies, psychoanalysis.

\section{ADOLESCENCE ET POLITIQUES PUBLIQUES : LA PRATIQUE PSYCHANALYTIQUE DANS DES INSTITUTIONS POUR MINEURS}

\section{Résumé}

Cet article présente une lecture psychanalytique sur la pratique dans une institution pour adolescents nécessitant des mesures de protection par menace ou violation de leurs droits. Tout d'abord, quelques aspects des politiques publiques au Brésil concernant les adolescents seront abordés. Ensuite, l'approche psychanalytique vis-à-vis de l'adolescence servira de base pour, finalement, illustrer la possibilité de pratique psychanaly- 
tique avec des jeunes placés en foyer lescents sont placés dans cette insinstitutionnel, suivant les guides titution le moins de temps possible techniques (CNAS \&amp; CONAN- suite à une mesure judiciaire excepDA, 2009). L'objectif de ces centres tionnelle, dont le but est de garanest d'accueillir des adolescents vulné- tir le respect des droits des mineurs rables à cause de violation de droits ou de liens familiaux brisés ou fragilisés, afin de préparer leur réintégration dans leur famille ou de les placer dans une famille d'accueil. Les adocomme stipulé par la loi.

Mots-clés : foyer pour mineurs, adolescence, politiques publiques, psychanalyse.

Recibido: 07/12/2018 • Aprobado: 21/03/2019 


\section{Adolescência e política pública: a prática psicanalítica em abrigo institucional}

\section{Assistência social e políticas públicas para o adolescente}

O tema da assistência social enquanto política pública brasileira é o ponto de partida para localizar a prática com adolescentes em abrigo institucional. A Constituição Federal de 1988 é o principal marco histórico, pois, pela primeira vez, se inscreve a política de Assistência Social, como um dos três pilares da seguridade social e regulada pela legislação.

A Assistência Social, a partir dessa legislação, começa a se configurar como uma política de garantia de direitos (política social, direito do cidadão e dever do Estado), algo inédito até então.

Art. 203. A assistência social será prestada a quem dela necessitar, independentemente de contribuição à seguridade social, e tem por objetivos:

I - a proteção à família, à maternidade, à infância, à adolescência e à velhice;

II - o amparo às crianças e adolescentes carentes;

III - a promoção da integração ao mercado de trabalho;

IV- a habilitação e reabilitação das pessoas portadoras de deficiência e a promoção de sua integração à vida comunitária;

$\mathrm{V}$ - a garantia de um salário mínimo de benefício mensal à pessoa portadora de deficiência e ao idoso que comprovem não possuir meios de prover à própria manutenção ou de tê-la provida por sua família, conforme dispuser a lei. ${ }^{3}$

Um dos marcos para a efetivação da política pública é a promulgação da Lei Orgânica da Assistência Social (LOAS) - Lei n ${ }^{\circ} 8.742$

3 Cabe ressaltar que as expressões "carentes" (inciso II) e "pessoa portadora de deficiência" (incisos IV e V) caíram em desuso e, atualmente, foram substituídas respectivamente por "em situação de vulnerabilidade e risco social" e "pessoas com deficiência". 
de 1993 (atualizada pela Lei $\mathrm{n}^{\circ} 12.435$ de 2011) -, regulamenta-se a prática prevista pela Constituição Federal estabelecendo critérios à organização da Assistência Social. A LOAS define, entre outros, as diretrizes, as atribuições de cada esfera da administração pública, os benefícios e serviços e o modo de financiamento das ações.

Além dela, a implementação do Sistema Único da Assistência Social (SUAS) através da elaboração/atualização da Política Nacional de Assistência Social - PNAS (2004) -, da Norma de Operação Básica (NOB/SUAS, 2005a) e da Norma Operacional Básica de Recursos Humanos do SUAS - NOB-RH/SUAS (2006) - pelo Ministério de Desenvolvimento Social e Combate à Fome vem para operacionalizar a política pública e transformar em ações diretas os princípios e diretrizes da Constituição Federal e da LOAS. "O SUAS é um sistema público não contributivo, descentralizado e participativo que tem por função a gestão do conteúdo específico da assistência social no campo da proteção social brasileira" (MDS, 2005a, p. 13).

O SUAS se divide em dois eixos: proteção social básica e proteção social especial. Ambas consistem no conjunto de ações, serviços e programas ofertados pelo SUAS a seus usuários; a diferença é que, na primeira, trata-se de prevenir situações de risco e vulnerabilidade social através do desenvolvimento de potencialidades do indivíduo e o fortalecimento de vínculos familiares e comunitários. Já a proteção social especial visa prover ações de atenção socioassistencial a famílias e indivíduos em situação de risco social devido à violação de direitos e/ou ameaça - abandono, maus tratos, abuso sexual, violência, trabalho infantil, cumprimento de medidas socioeducativas, situação de rua, entre outros.

O abrigo institucional está inserido na rede de serviços ofertados pela proteção social especial, pois se trata de um trabalho voltado a crianças e adolescentes vítimas de qualquer tipo de violência, maus tratos, abandono, negligência, ou sob algum tipo de ameaça.

$\mathrm{Na}$ onda da Constituição Federal, promulga-se uma importante lei que concerne à infância e à adolescência: o Estatuto da Criança e do Adolescente (ECA), Lei $n^{\circ} 8.069$ de 1990, que representa a regulamentação do art. 227 da Constituição Federal, que elenca a criança e o 
adolescente (e posteriormente acrescenta-se o jovem [Emenda Constitucional $\mathrm{n}^{0} 065$ de 2010]) como público prioritário do cuidado da família, da sociedade e do Estado.

O ECA delimita, através de parâmetro etário, qual o público alvo dessa lei, ao qual se deve garantir a proteção integral: considera-se uma criança toda pessoa de zero a doze anos incompletos, e adolescente aquela de doze a dezoito anos incompletos.

Com o ECA reconhece-se, pela primeira vez, a criança e o adolescente como sujeitos de direitos e se estabelece os deveres da família, da comunidade, da sociedade em geral e do Poder Público, conforme apontam os artigos $3^{\circ}$ e $4^{\circ}$ :

Art. $3^{\circ}$. A criança e o adolescente gozam de todos os direitos fundamentais inerentesà pessoa humana, sem prejuízo da proteção integral de que trata esta Lei, assegurando-se-lhes, por lei ou por outros meios, todas as oportunidades efacilidades, a fim de lhes facultar o desenvolvimento físico, mental, moral, espirituale social, em condições de liberdade e de dignidade.

Art. $4^{\circ}$. É dever da família, da comunidade, da sociedade em geral e do Poder Públicoassegurar, com absoluta prioridade, a efetivação dos direitos referentes à vida, à saúde, à alimentação, à educação, ao esporte, ao lazer, à profissionalização, à cultura, à dignidade, ao respeito, à liberdade e à convivência familiar e comunitária.

Parágrafo único. A garantia de prioridade compreende:

a) primazia de receber proteção e socorro em quaisquer circunstâncias;

b) precedência do atendimento nos serviços públicos ou de relevância pública;

c) preferência na formulação e na execução das políticas sociais públicas;

d) destinação privilegiada de recursos públicos nas áreas relacionadas com aproteção à infância e à juventude. (Grifos nossos).

O ECA, de partida, é a lei que estabelece que crianças e adolescentes são sujeitos de direito. É uma lei decorrente, segundo Digiá- 
como (2013), do artigo $5^{\circ}$ da $C F / 88$, que confere a todos a igualdade de direitos e deveres individuais e coletivos. Embora sob a égide da igualdade, às crianças e aos adolescentes lhes é atribuída a condição peculiar de "pessoas em desenvolvimento" (ECA, artigo $6^{\circ}$ ).

Se, a partir da nova legislação, inaugura-se a atribuição de direitos a esse público, abre-se também a perspectiva para esses direitos serem violados ou ameaçados:

Art. 98. As medidas de proteção à criança e ao adolescente são aplicáveis, sempre que os direitos reconhecidos nesta Lei forem ameaçados ou violados:

I - por ação ou omissão da sociedade ou do Estado;

II - por falta, omissão ou abuso dos pais ou responsável;

III - em razão de sua conduta.

$\mathrm{O}$ acolhimento institucional figura entre as possibilidades de medidas de proteção, quando os direitos de crianças e adolescentes são violados ${ }^{4}$. Esse é o ponto que concerne ao tema deste artigo. $\mathrm{O}$ acolhimento institucional é uma das medidas protetivas e possui princípios bem delimitados. Já citado no artigo $4^{\circ}$, o direito à convivência familiar e comunitária é retomado no artigo 19, no qual se estabelece que toda criança e adolescente possui o direito de ser criado e educado no seio de sua família e, excepcionalmente, em uma família substituta. No entendimento da lei, o desenvolvimento da criança e do adolescente em programa de acolhimento é prejudicial. Portanto esta é uma medida de caráter provisório, excepcional e deve durar o menor tempo possível ${ }^{5}$.

Todos os esforços devem ser empreendidos no sentido de manter o convívio com a família (nuclear ou extensa, em seus diversos arranjos), a fim de garantir que o afastamento da criança ou do adolescente do contexto familiar seja uma medida excepcional, aplicada apenas nas situações de grave risco à sua integridade física e/ou psíquica.

4 ECA, artigo 101, inciso VII.

5 Segundo o ECA, até no máximo dois anos, sendo reavaliado a cada seis meses. 
Como este afastamento traz profundas implicações, tanto para a criança e o adolescente, quanto para a família, deve-se recorrer a esta medida apenas quando representar o melhor interesse da criança ou do adolescente e o menor prejuízo ao seu processo de desenvolvimento. Destaca-se que tal medida deve ser aplicada apenas nos casos em que não for possível realizar uma intervenção mantendo acriança ou adolescente no convívio com sua família (nuclear ou extensa). (CNAS \& CONANDA, 2009, p. 18).

Desse modo, o acolhimento é compreendido como o momento de transição para a reintegração familiar ou colocação em família substituta. Outro aspecto que deve ser destacado é que o acolhimento institucional não acarreta a privação de liberdade; pelo contrário, a política pública preconiza a convivência comunitária.

A relação do acolhimento a crianças e adolescentes com a Assistência Social é que os serviços de acolhimento necessariamente estão inseridos na rede de acompanhamento do SUAS, mais precisamente da Proteção Social Especial, que é o circuito de acompanhamento para casos nos quais se observa a ameaça ou violação de direitos.

É importante frisar que o ECA representa um rompimento com o Código de Menores de 1979 (uma versão atualizada do código de mesmo nome, de 1927), que tratava de medidas relativas ao "menor em situação irregular". Rompe-se, portanto, com a concepção estigmatizante do "menor" e se estabelece direitos para a criança e para o adolescente. Nota-se a mudança da terminologia para tratar do público em questão: o Código de Menores refere como "menor" - termo de cunho discriminatório - toda pessoa até dezoito anos e, consideradas as exceções, até vinte e um anos.

Considerando nosso foco sobre a adolescência e não sobre a infância, nos questionamos de que se trata tal etapa da vida.

O termo "adolescente" surge de forma inédita em uma legislação brasileira na Constituição Federal de 1988, através do artigo 227. Para fins legais e de política pública, o que se entende por um adolescente é bem claro e não deixa margens de dúvida. Como visto acima, a idade cronológica o define: segundo o ECA, é adolescente todo sujeito de 12 a 18 anos incompletos. 
Digiácomo (2013), ao comentar sobre o ECA, destaca o caráter objetivo da delimitação etária nos procedimentos legais:

O presente dispositivo conceitua, de forma objetiva, quem é considerado criança e quem é considerado adolescente, para fins de incidência das disposições contidas no ECA (que em diversas situações estabelece um tratamento diferenciado para ambas categorias - vide, por exemplo, o disposto nos arts. $45, \S 2^{\circ}$ e 105 , do ECA). Trata-se de um conceito legal e estritamente objetivo, sendo certo que outras ciências, como a psicologia e a pedagogia, podem adotar parâmetros etários diversos (valendo também mencionar que, nas normas internacionais, o termo "criança" é utilizado para definir, indistintamente, todas as pessoas com idade inferior a 18 anos). (Digiácomo, 2013, p. 4).

Que consequências tem uma legislação que delimita a idade do adolescente? Ela garante a passagem pela adolescência, o que implica também a obrigatoriedade de se sair dela: ao completar 18 anos, o sujeito é juridicamente "expulso" da adolescência.

\section{A adolescência para a psicanálise}

A partir da Psicanálise, podemos ir além da perspectiva cronológica. $O$ decisivo se trata da transição psíquica, no sentido de atualização das escolhas objetais e posição dos sintomas e fantasias. No contexto do trabalho clínico na instituição, a margem de idade imposta pela lei é relevante, mas o que está em questão para o psicanalista é o percurso singular de cada sujeito, como se dá o encontro com o Outro sexo e a solução para concluir essa etapa. $\mathrm{O}$ encontro entre idade cronológica e adolescência é meramente contingente.

Para compreender a passagem da infância para a vida adulta, Freud (1996/1905), em os "Três ensaios sobre a teoria da sexualidade", faz elaborações sobre o desenvolvimento da pulsão sexual. Segundo ele, a pulsão sexual está presente desde a infância, quando se satisfaz no próprio corpo. Portanto, nessa etapa, não está dirigida à outra pessoa. Freud denomina zonas erógenas as partes do corpo que se destacam como áreas da satisfação sexual: "Trata-se de uma parte da pele ou da mucosa em que certos tipos de estimulação pro- 
vocam uma sensação prazerosa de determinada qualidade" (Freud, 1996/1905, p. 172).

Assim, para Freud (1996/1905), a pulsão sexual, durante o período da infância, possui caráter auto-erótico, ou seja, é através do próprio corpo que o sujeito satisfaz a pulsão. Por exemplo, o ato de amamentar-se no seio materno comporta, inicialmente, uma necessidade de alimentação e adquire, depois, uma função independente de atividade sexual, pois o prazer do ato de sucção faz da zona oral uma via de satisfação sexual: o prazer vivenciado é retomado para além da necessidade orgânica de alimentação. Progressivamente, outras zonas são notadas pelo autor como condensadoras para a satisfação sexual auto-erótica.

Nesse contexto, o tema da puberdade surge como decisivo, pois as transformações dessa etapa conduzem à passagem da vida sexual auto-erótica para a busca da satisfação da zona genital por meio do encontro com outro sujeito. A partir da puberdade, a zona genital, numa perspectiva de desenvolvimento da pulsão dito normal, assume uma função privilegiada. Isso não significa que as fixações libidinais infantis sejam abandonadas por completo - elas seguem como fonte de satisfação para o sujeito. A puberdade é, porém, o momento de convocação para o sujeito se lançar ao encontro sexual. Segundo Freud (1996/1905), a tensão sexual e o prazer que a ela sucede já são experimentados na infância, o que advém somente na puberdade é a experiência do prazer final ou prazer de satisfação da atividade sexual.

Outro aspecto importante sobre a etapa da puberdade é a definição nítida dos caracteres masculinos e femininos. A atividade sexual auto-erótica é muito similar em ambos os sexos e o momento da puberdade é crucial para o sujeito se posicionar na partilha dos sexos. A primazia das zonas genitais precipita a identificação com o campo masculino ou feminino. A puberdade, além de configurar a nova e última etapa do fluxo do desenvolvimento da pulsão sexual (fase genital), promove o desligamento do sujeito da autoridade dos pais. Para que o sujeito possa lançar-se ao encontro amoroso, ocorre a superação da escolha objetal da fantasia primordial incestuosa, sem, no entanto, que essa fixação no objeto incestuoso deixe de ter repercussões. 
Nos artigos "A organização genital infantil: uma interpolação na teoria da sexualidade" e "A dissolução do complexo de Édipo", Freud $(1996 / 1923 ; 1996 / 1924)$ destaca a primazia do falo no processo de desenvolvimento sexual infantil. O órgão genital masculino é o operador para se estabelecer a diferença entre os sexos. A primazia do falo é essencial na teoria freudiana do complexo de castração. A ameaça de perder o pênis, por parte do menino, e a inveja por não tê-lo, por parte da menina, se desdobram, no período da infância, na questão entre possuir o órgão genital masculino ou ser castrado. Apenas na puberdade, segundo Freud (1996/1923), se estabelece a polaridade masculino e feminino de forma completa. Esse processo se relaciona com a dissolução do complexo de Édipo, pois a ameaça de castração faz o sujeito, no fim do processo, abandonar a relação incestuosa, não sem que esta deixe marcas na formação dos sintomas e da fantasia.

Lacan (2003/1974), em "Prefácio a O despertar da primavera", para a obra de Frank Wedekind, elabora sobre a relação do advento da puberdade com a sexualidade. Segundo ele, a peça em questão tem êxito em demonstrar que a relação sexual é mal sucedida para qualquer sujeito falante, ideia que estaria presente desde Freud. O gozo fálico responde pela relação entre sentido e gozo e a puberdade (ou a adolescência, se podemos dizer) desvela o descompasso entre esses elementos. Pois, para Lacan (2003/1974), a sexualidade, desde Freud, faz um furo no real do qual ninguém escapa ileso. O sujeito púbere, ao lançar-se no Outro social como participante da contingência do encontro sexual, se depara com o real da não-relação. O que Lacan (2003/1974) almeja demonstrar é que não há rito ou convenção social que faça convergir gozo e sentido de forma estável. Algo resta. O gozo está mais ligado à transposição da barreira do véu do que ao encontro com o objeto, o que torna essa operação inesgotável.

Portanto, a "novidade" que a adolescência comporta, se assim podemos chamar, é o encontro inevitavelmente mal sucedido com o real do sexo. A promessa da infância do gozo fálico revela um sabor de decepção quanto ao objetivo almejado, o que convoca o sujeito a uma reconfiguração da fantasia e do sintoma. Notemos que esse processo não se relaciona com a maturação do corpo biológico e nem com 
o desenvolvimento cronológico do sujeito. A adolescência não é sem as mutações do corpo púbere, mas a transformação psíquica exigida ultrapassa qualquer apreensão físico-química, hormonal ou etária.

Miller (2016/2015), na intervenção "Em direção à adolescência", assinala a diversidade de definições sobre a adolescência: pode-se interpretá-la sob o viés da cronologia, da biologia, da psicologia, da sociologia ou do campo estético-artístico. Isso não significa que uma se sobressaia em relação às outras, ou que possamos dissecá-la em partes. Para esse autor, o decisivo é conceber a adolescência como uma construção, um artifício significante em conformidade com nossa época.

Segundo Miller (2016/2015), há três aspectos fundamentais sobre o tema da adolescência:

1) A saída da infância. Como Freud aborda em "Os três ensaios", trata-se do momento lógico precipitado pela puberdade, em que o sujeito é convocado a lançar-se ao encontro com o corpo do Outro - a satisfação auto-erótica não é abandonada, mas uma nova modalidade do campo sexual urge de se efetivar.

2) A diferença dos sexos. A puberdade representa uma escansão sexual, ou seja, há, na puberdade, um ponto de convergência para que o sujeito se situe em relação à sexualidade, conforme trabalhado acima. A adolescência é parada obrigatória no fluxo da sexualidade do sujeito.

E, finalmente: 3) A imiscuição do adulto na criança. Segundo Miller (2016/2015), há uma espécie de antecipação da posição adulta na criança - não se pode precisar os momentos de tal imiscuição. De acordo com esse autor, o momento púbere é aquele em que se reconfigura o narcisismo.

No artigo "Adolescência, sintoma da puberdade", Stevens (2004/1998) propõe a adolescência como o momento de uma variedade de respostas possíveis ao impossível que é o surgimento do real próprio da puberdade. O sujeito é convocado a responder, pela via sintomática, à ausência da relação sexual, no sentido do furo constitutivo que há no circuito da sexualidade. 
O que quero precisar é que essas escolhas deverão ser recolocadas tanto do lado da fantasia, que vai ser posta à prova na puberdade, quanto do lado do sintoma, que assume formas variadas. Essas escolhas vão ser recolocadas mesmo se a estrutura está, sem dúvida, já decidida, neurose ou psicose, e mesmo no interior das neuroses, a obsessão ou a histeria. Contudo, as formas comportamentais, as formas fenomenais e também a relação do sintoma com o sexo vão se encontrar modificadas na puberdade. (Stevens, 2004/1998, p. 29).

Stevens (2004/1998) elabora uma articulação precisa entre puberdade e adolescência. A primeira representa o momento em que a não-relação aparece para o sujeito, é o surgimento do real próprio da sexualidade. Ao passo que a adolescência é a resposta sintomática possível adotada pelo sujeito. A adolescência tem função de metáfora, por fazer representar o furo indizível da sexualidade. O arranjo sintomático do sujeito, sempre singular, representa uma tentativa mais ou menos estável de enodar gozo e corpo.

De que real se trata? Como aponta Stevens (2004/1998), para relacionar a libido com a adolescência, devemos tomar o real da puberdade como orgânico, desde que se considere o órgão não no sentido hormonal, biológico ou médico, mas na concepção lacaniana: o órgão da libido como órgão fora do corpo. Portanto, o gozo possui uma dimensão estrangeira ao próprio corpo do ser falante. O órgão da libido é marcado pelo discurso e não reduzido somente à modificação anatômica. O real em questão é o da transformação de um órgão marcado pela linguagem. Trata-se de uma irrupção sobre a qual as palavras falham, é a emergência de um novo para o qual a fantasia do sujeito vacila e, por isso, necessita se atualizar.

Ao contrário dos animais, o ser humano não possui um saber prévio sobre a copulação. $\mathrm{O}$ ser falante não se orienta pelo instinto, pois a operação de constituição do sujeito a partir do Outro, sob a extração do significante, inaugura uma marca indelével que não é universal. Portanto: "o real da puberdade é a irrupção de um órgão marcado pelo discurso na ausência de um saber sobre o sexo, na ausência de um saber sobre o que se pode fazer em face de outro sexo" (Stevens, 2004/1998, p. 35). 
Como pode a Psicanálise constituir uma orientação, digamos, de nível metodológico, para o trabalho em uma instituição estatal de acolhimento para adolescentes em situação de violação de direitos?

De acordo com o ECA (artigo $4^{\circ}$ ), a convivência familiar e comunitária é direito de toda criança e adolescente. Considera-se prejudicial o processo de desenvolvimento infanto-juvenil fora do ambiente familiar. A política pública enfatiza a importância desse tipo de interação para o desenvolvimento da criança e do adolescente. Em conformidade com a política pública, nessa etapa do desenvolvimento humano esses vínculos "são fundamentais para oferecer-lhes condições para um desenvolvimento saudável, que favoreça a formação de sua identidade e sua constituição como sujeito e cidadão." (CNAS \& CONANDA, 2009, p. 20). Notamos, assim, que esse princípio orienta toda a prática institucional, de forma que a intervenção jurídica do acolhimento adquire caráter excepcional e breve. Além disso, a reintegração familiar se torna o objetivo máster das ações.

No entanto, observa-se, na maioria dos casos, que a violação de direitos que acarreta a retirada do adolescente de seu meio familiar é justamente oriunda da relação com os entes familiares. Notam-se episódios de violência física, agressão, abuso sexual, negligência, entre outros, no próprio circuito familiar. Ou seja, o ambiente dito saudável para o desenvolvimento de crianças e adolescentes é também onde a violência se faz presente.

Ora, como compreender esse fenômeno? Seria, paradoxalmente, a própria família um lugar de risco para a criança e o adolescente? E se invertêssemos a pergunta: não é toda família estruturalmente violenta?

M.-H. Brousse (2017a/2016; 2017b/2016), nas conferências “Violencia en la cultura: de la violencia legitimizada a la radicalización de la violencia" e "Violencias en la familia. Pegar e ser pegado", questiona sobre o estatuto atual da violência em relação ao laço social. De partida, traça um aspecto ético fundamental: é preciso separar a violência de toda moralização, ao contrário do que acontece, por exemplo, nos meios de comunicação e mídia. Isso quer dizer que a condenação da violência como mal contemporâneo já nos afasta do cerne da questão, que é compreender a violência como inerente à ci- 
vilização. Ou seja, a relação entre violência e laço social não se dá devido à contingência. O laço social em si é violento; a civilização não se constitui sem a violência.

O laço social é um discurso e, como aponta Brousse (2017a/2016), é nele que se inscrevem as enunciações possíveis e efetivas. Através do sentido, o discurso consegue gerir os seres falantes, pois opera ordenando o que não tem sentido: o gozo. Portanto, cada versão histórica do discurso do mestre dá sentido ao gozo - todo discurso é uma hermenêutica imposta pelos significantes mestres.

Seguindo essa lógica, todo discurso é um discurso de dominação, pois inscreve a dominação de um modo de gozo sobre outro. Exceto o discurso analítico, que faz exceção e que não pode ser o discurso dominante, pois ele justamente exclui a dominação - ele nada ensina, uma vez que nada tem de universal.

Para a autora, no entanto, em termos de gozo, a articulação entre castração e Nome-do-Pai deixou de funcionar. Isso é o que caracteriza a modernidade. A violência no âmbito do Nome-do-Pai funcionava em termos de castigo, sacrifício, deveres, direitos... Havia diversos modos para se dar sentido à captura significante do gozo, necessariamente violento. Quando o Nome-do-Pai cai ou tem menos poder, o que se torna mais poderoso é o supereu, que não está associado a nenhum nome, somente a um imperativo.

Ora, como já colocado, desde a Constituição Federal e o Estatuto da Criança e do Adolescente, o adolescente possui direitos. $\mathrm{O}$ acolhimento para crianças e adolescentes se destina a sujeitos que tiveram seus direitos violados e que necessitam de amparo ou proteção institucional. Os artigos 100 e 101 do ECA tratam de uma gama de medidas de intervenção por parte das autoridades face às situações de perigo para essa clientela, dentre as quais figura o acolhimento. Portanto, na lógica judicial, esses sujeitos são compreendidos como vítimas. Que significa esse estatuto de vítima e quais as consequências para o acompanhamento?

$\mathrm{O}$ atendimento a uma clientela supostamente vítima perpassa a política pública da Assistência Social, que dedica à proteção social especial um trabalho direcionado aos sujeitos que tiveram direitos violados ou correm algum risco nesse domínio: 
a proteção social especial tem por direção: a) proteger as vítimas de violências, agressões e as pessoas com contingências pessoais e sociais, de modo a que ampliem a sua capacidade para enfrentar com autonomia os revezes da vida pessoal e social; b) monitorar e reduzir a ocorrência de riscos, seu agravamento ou sua reincidência; c) desenvolver ações para eliminação/redução da infringência aos direitos humanos e sociais. Este campo de proteção na assistência social se ocupa das situações pessoais e familiares com ocorrência de contingências/vitimizações e agressões, cujo nível de agravamento determina seu padrão de atenção. (MDS, 2009, p. 3).

Portanto, é necessário, sim, tomar a política pública como a dimensão universal, como a vertente do "para todos", ou seja, a instância garantidora de direitos. Porém, não devemos alienar o sujeito e suas particularidades aos princípios da lei para dar consistência à própria legislação, que, por definição, elabora sobre a normatividade.

$\mathrm{Na}$ rede de acompanhamento, o abrigo institucional tem um papel de receber adolescentes quando seus direitos já foram violados ou estão sob ameaça. Portanto, eles são inseridos na instituição com o estatuto de vítima, judicialmente avaliado.

Questões que surgem: o adolescente em unidade de acolhimento é uma vítima? Que significa essa posição de vítima?

A disposição da política pública pode produzir a redução dos sujeitos adolescentes a objeto, posição desumanizada de vítima que caminha na contramão da perspectiva da singularidade do sujeito, como demarca Célio Garcia (2009):

Essa definição vai incluir o não-humano; para tanto, temos que romper com a concepção cada vez mais aceita na atualidade e que consiste em ver na maioria das vezes o homem como uma vítima; os direitos desse homem-vítima serão consequentemente, os direitos de uma vítima, e o tratamento a ele reservado será um tratamento reservado a uma vítima.

O estado de vítima, de desamparado, de infeliz, de humilhado, reduz o homem à sua condição animal. Certamente que a humanidade é uma espécie animal, mortal e cruel.

Mas nem a mortalidade, nem a crueldade definem a singularidade humana. (Garcia, 2009, n.p.) 
Bassols (2014) assinala que, a partir de meados do século xx, a criminologia e o discurso jurídico passam a se questionar não somente sobre a delinquência e o ato criminoso, mas também sobre a figura da vítima. Surge, segundo ele, mais precisamente no fim do século passado, uma nova forma de conceber a vítima. Devido à defesa de direitos de grupos isolados, o objeto vítima passou a representar não um sujeito singular, mas uma comunidade. Esse fenômeno se constitui pela identificação do sujeito ao objeto vítima, a partir de algum traço, de forma massiva e coletivizada, o que causa uma desresponsabilização do sujeito com relação à sua posição de objeto. De acordo com o autor, extrai-se daí uma diferença entre uma vitimização primária - quando há uma identificação ao objeto vítima diante do acontecimento traumático e delituoso - e uma vitimização secundária - quando o sujeito se situa como objeto vítima diante de um Outro social e jurídico independentemente das contingências, pelo simples pertencimento a um grupo ou coletivo. Esta segunda concepção pode ter efeito desastroso se atribuir aos sujeitos sua posição de vítima, pois provoca uma desresponsabilização do sujeito concernente à sua resposta singular de se constituir a partir da condição de objeto do Outro.

Neste momento, cabe perguntar: todo adolescente acolhido em abrigo institucional é uma vítima? Segundo o diagnóstico da autoridade judicial, sim. Para a Psicanálise, é necessário um trabalho com cada sujeito para localizar sua posição em relação à sua trama familiar, sua história, suas escolhas. Através da escuta psicanalítica, pode se produzir um sujeito para além da posição de objeto vítima.

\section{Um acompanhamento psicanalítico na construção de um lugar} para si

Elegemos um caso para orientar a discussão dessas questões. Sérgio, de 14 anos, veio de outro estado, foi enviado pela avó paterna para passar férias com o pai (único membro da família nesta região). Todavia, ao chegar, descobriu que o plano da avó era que ele ficasse com o pai definitivamente, devido à sua dificuldade financeira. Morando com o pai, envolve-se com "más amizades", jovens com envolvimento no tráfico, e retoma o uso de drogas. O pai, ao descobrir, o 
agride para "corrigi-lo", brigaram a tal ponto que o adolescente decidiu morar na rua. Ao tomar conhecimento da situação, o Conselho Tutelar encaminha o adolescente para o abrigo, onde ele permanece sob determinação judicial. A decisão inicial da justiça não determinou que ele fosse acompanhado à sua cidade de origem em outro estado, embora ele tivesse parentes dispostos a recebê-lo, o que gerou a adaptação do adolescente à cidade e ao abrigo.

Deu-se a interação comunitária de Sérgio: voltou à escola, fez amizades, realizou curso profissionalizante de barbeiro, frequentou a igreja na cidade e começou a namorar uma colega da escola. Por um lado, Sérgio se engajou no laço social através de semblantes de grupos fora da lei associados ao tráfico de drogas, utilizando essa linguagem para sustentar uma posição de poder e influência diante dos outros adolescentes; por outro lado, apresentava cooperação e respeito para com os adultos e profissionais da escola e do abrigo, posição que se abalava nos momentos que abusava de drogas ou se engajava mais com as amizades do tráfico.

Ele realizou tratamento no CAPS ad do município, onde uma das atividades de seu projeto terapêutico era cortar cabelo de outros pacientes. Segundo ele, o espaço desse serviço era importante para ele conversar e conseguir reduzir seu consumo de maconha, substância que, na ocasião, era mais problemática para ele.

Sobre o histórico familiar do adolescente: sua mãe é usuária de drogas e, segundo ele, fica a esmo pelas ruas. Sérgio já havia passado por uma instituição de acolhimento com suas três irmãs mais novas até que a avó materna assumiu a guarda. Posteriormente, ela manteve as irmãs e entregou Sérgio (único filho desse pai) à avó paterna, que, em seguida, o manda para o pai. Até então, convivera muito pouco com este e chegou a ficar anos sem ter notícias dele.

Decorreu que Sérgio não quis mais voltar ao estado de origem, pois teria, segundo ele, mais oportunidades aqui e, caso retornasse, voltaria a usar drogas, além de trazer à tona uma ameaça sofrida por um policial que supostamente queria matá-lo.

$\mathrm{Na}$ audiência seguinte, Sérgio manifestou o desejo de continuar na instituição, mostrou-se irredutível em relação a seu genitor afir- 
mando que não tem mais pai, que seu pai é Deus. A juíza, nitidamente desconcertada com a demanda do adolescente, lhe permitiu permanecer no abrigo até que ele concluísse seu curso profissionalizante no mês seguinte. Ele também recusou a proposta de retornar a seu estado de origem para morar com a avó materna, disposta a recebê-lo. Estava decidido a evadir-se da instituição, se fosse obrigado a deixar a cidade.

Lacadée (2011) reflete sobre qual a função do psicanalista para com o adolescente. $\mathrm{O}$ espaço de fala do dispositivo da psicanálise oferece um enquadre de liberdade possível para o sujeito expressar a via do novo no dizer. Pode-se, então, depositar um resto inassimilável, o real insuportável, o indizível, algo de intratável. Por meio desse movimento, se inaugura uma forma de se localizar frente ao gozo inédito, a possibilidade de se situar no mundo e no laço social, a partir do que há de mais singular. Disso decorre a hipótese do autor de atrelar a transição da adolescência à tarefa de tradução.

O novo surgido no dito pode, então, orientar uma fala inédita, uma nova tomada de posição na língua, permitindo ao adolescente traduzir a via nova que a ele oferecida. Eis o abrigo que pode oferecer o encontro com um psicanalista, guiando o adolescente na tarefa de bem dizer seu ser. (Lacadée, 2011, p. 23).

A palavra "abrigo", conforme apresentada por Lacadée (2011) nesse trecho, nos faz despertar para um acolhimento que deve ser ofertado não na via institucional, mas através do dispositivo de fala. Podemos ir mais longe: o abrigo, por excelência, que deve ser ofertado aos adolescentes sob medida protetiva do Estado, é o acolhimento ao singular que se extrai da escuta clínica. $\mathrm{O}$ aparato institucional, sem a possibilidade de reconhecer o caso-a-caso, acarreta necessariamente o processo de segregação do sujeito, pois se reduz a demanda do sujeito às necessidades. Além disso, acaba-se por interpretar os princípios da lei sob um imperativo feroz, que não permite a flexibilidade da instituição para acolher os adolescentes. $\mathrm{O}$ objetivo de garantir direitos aos adolescentes só pode ser validado se tomarmos a legislação em articulação com cada caso. Se o acompanhamento se dá de forma generalista, identificamos que, de algum modo, há um 
retorno à prática do modelo dos internatos-prisão, embora sob um suposto viés de humanização e garantia de direitos.

Com relação às referências familiares e simbólicas, como Sérgio se situa? Apresentava-se dividido em relação ao pai: ora ficava esperançoso de retomarem uma relação, quando o pai o visitava ou ia à instituição para conversar com a equipe, ora o descartava de sua vida, quando o pai, por exemplo, não o procurava. Disse que se encontraram na rua e o pai não o olhou - como quem não o reconhecia. A demanda de reconhecimento pelo pai foi um tema importante para Sérgio que revelou que, em momentos de angústia, recorria de forma abusiva à maconha. Referia bastante afeto com relação às irmãs e à avó materna, esta ligava bastante para o abrigo e ansiava pelo retorno de Sérgio. Ele descartava voltar à cidade de origem, mas tinha o objetivo de recebê-las para morar com ele. Sérgio falava pouco sobre sua mãe, citava-a com desdém, como alguém com quem ele não poderia contar. Eu me questiono se não haveria um ressentimento muito cristalizado dele em relação a ela.

Meu trabalho com Sérgio procurava acompanhá-lo na construção de um lugar para si. Um lugar que envolvia não só a problemática sobre onde morar e com quem, mas também situar suas referências, seus pontos de ancoragem, suas metas, a construção de possibilidades futuras que o fizessem caminhar, etc. Ofertei um espaço que não visava necessariamente a resolver o impasse sobre onde moraria, ou a tratar das questões disciplinares que envolviam sua rotina e seu comportamento na instituição. A sutileza do trabalho realizado envolvia menos a resolução do para onde ir do que o uso que ele poderia fazer das referências familiares para prescindir da autoridade parental. Entendo que toda a elaboração sobre os membros de sua família operou para localizá-lo na teia familiar e se orientar na caminhada para a vida adulta.

Esse nó do caso, sobre o local onde Sérgio deveria morar e com quem, atravessou todo o acompanhamento ao adolescente. Na interlocução com os profissionais do judiciário, da rede socioassistencial e do próprio serviço, procurei manter viva a discussão do caso. Sem rechaçar a opinião daqueles que indicavam seu encaminhamento imediato para ele morar com parentes em seu estado de origem, procurei 
apontar posicionamentos de Sérgio que não corroboravam com essa indicação.

Diante das demandas do judiciário sobre os adolescentes acolhidos e suas famílias, nos parece que a função do psicanalista é transmitir a dimensão do caso-a-caso como um furo, apontar no sentido do real e não fornecer supostas soluções à autoridade jurídica, por exemplo. É justamente por fracassar o atendimento à demanda do judiciário que se viabiliza a escuta psicanalítica em órgãos e instituições articuladas ao campo do direito. Faz-se necessária uma subversão dessa demanda para o psicanalista não encarnar a função de perito e reduzir o adolescente a objeto.

Como visto até aqui, há uma tensão no acompanhamento institucional aos adolescentes entre a estrutura do "para todos" e o singular de cada caso. Entendemos que o trabalho do psicanalista opera num fluxo entre essas instâncias, a fim de evitar que as generalizações sufoquem as diferenças. A psicanálise propõe uma solução que dê lugar ao singular de cada um para, com isso, humanizar os sujeitos.

já não se tratará de compor um conjunto através de um somatório das pequenas diferenças, mas de compor ou conviver com os coletivos levando-se em conta a exceção que o cada um representa. Sendo assim, a relação entre o para todos e o cada um muda completamente: a loucura de cada um não será uma doença, uma excrescência, ou uma patologia do para todos, mas a sua causa. Este seria o lugar da psicanálise: ajudar a manter as chances do singular é a sua tarefa clínica, mas, além disso, é também um ensinamento que tem para dar à civilização. A relação entre o para todos e o cada um está no coração da política lacaniana. (Rêgo-Barros, 2011, p. 195).

Este trecho de Romildo do Rêgo Barros (2011) nos é útil para elaborarmos sobre o papel da Psicanálise. Segundo ele, é na articulação entre esses dois elementos heterogêneos - o para todos e o cada um - que a Psicanálise deve se situar. Sua função é possibilitar o encontro entre eles, mesmo que pela via do contraste ou do choque.

Tomar cada caso como singular necessariamente faz ruir a política pública a cada encontro, pois a experiência analítica incide sobre 
o gozo do sujeito, aquilo que é tão único a ponto de desmontar qualquer tentativa de generalização dos sujeitos. É fundamental explicar que não é que a política pública não seja importante para a Psicanálise, ou que o analista queira prescindir dela: o decisivo é como cada sujeito se posiciona no laço social, a partir da mudança de seu programa de gozo proporcionada pelo encontro com o analista.

\section{Referencias}

Bassols, M. (18 de novembre de 2014). Victimología. Desescrits: de psicoanàlisi lacaniana. Recuperado en http://miquelbassols.blogspot. com/2014/11/victimologia.html.

Brasil. (2012). Constituição (1988). Constituição da República Federativa do Brasil: texto constitucional promulgado em 5 de outubro de 1988, com as alterações adotadas pelas Emendas Constitucionais nos 1/1992 a 68/2011, pelo Decreto Legislativo $n^{\circ}$ 186/ 2008 e pelas Emendas Constitucionais de Revisão nos 1 a 6/1994. Brasília, Brasil: Edições Câmara dos Deputados. Recuperado de https://www2.senado.leg.br/bdsf/bitstream/ handle/id/518231/CF88 Livro EC91 2016.pdf.

Brousse, M.- H. (2017a/2016). Violencia en la cultura: de la violencia legitimizada a la radicalización de la violencia. Bitácora lacaniana: Violencia y explosión de lo real. Número extraordinario, abril de 2017, 9-20.

Brousse, M.- H. (2017b/2016). Violencias en la familia: pegar e ser pegado. Bitácora lacaniana: Violencia y explosión de lo real. Número extraordinario, abril de 2017, 21-36.

Conselho Nacional de Assistência Social (CNAS) \& Conselho Nacional dos Direitos da Criança e do Adolescente (CONANDA). (2009). Orientações técnicas: Serviços de acolhimento para crianças e adolescentes. Brasília, Brasil. Recuperado de: https://www.mds.gov.br/cnas/noticias/orientacoes tecnicas final.pdf.

Digiácomo, M. J. (2013). Estatuto da criança e do adolescente anotado e interpretado: Lei $\mathrm{n}^{\circ} 8.069$, de 13 de julho de 1990 (atualizado até a Lei $\mathrm{n}^{\circ}$ 12.796/2013, de 04 de abril de 2013). Curitiba, Brasil: Centro de Apoio Operacional das Promotorias da Criança e do Adolescente.

Freud, S. (1996/1905). Três ensaios sobre a teoria da sexualidade. En Freud, S. Obras psicológicas completas de Sigmund Freud. Ed. Standard Brasileira (Vol. VII, pp. 129-256). Rio de Janeiro, Brasil: Imago.

Freud, S. (1996/1923). A organização genital infantil: uma interpolação na teoria da sexualidade. En Freud, S. Obras psicológicas completas de 
Sigmund Freud. Ed. Standard Brasileira (Vol. XIX, pp. 179-188). Rio de Janeiro, Brasil: Imago.

Freud, S. (1996/1924). A dissolução do complexo de Édipo. En Freud, S. Obras psicológicas completas de Sigmund Freud. Ed. Standard Brasileira (Vol. XIX, pp. 217-228). Rio de Janeiro: Imago.

Garcia, C. (17 de julio de 2009). A vítima, sua vez, sua voz. Recuperado en http://www.jorgeforbes.com.br/br/movimento-analitico/de-celio-garcia-2.html.

Lacadée, P. (2011). O despertar e o exílio: ensinamentos psicanalíticos da mais delicada das transições, a adolescência. Rio de Janeiro, Brasil: Contra Capa Livraria.

Lacan, J. (2003/1974). Prefácio a O despertar da primavera. En Lacan, J. Outros escritos (pp. 557-559). Rio de Janeiro, Brasil: Jorge Zahar Ed.

Miller, J.-A. (2016/2015). Em direção à adolescência. En H. Caldas, A. Bemfica \& C. Boechat (Comps.). Errâncias, adolescências e outras estações (pp. 19-33). Belo Horizonte, Brasil: Editora EBP.

Ministério do Desenvolvimento Social e Combate à Fome de Brasil (MDS). (1993). Lei $\mathrm{n}^{\circ} 8742$ de 7 de dezembro de 1993. LOAS anotada. Lei orgânica de assistência social. Recuperado de: http://www.mds.gov.br/webarquivos/publicacao/assistencia_social/Normativas/LoasAnotada.pdf.

Ministério do Desenvolvimento Social e Combate à Fome de Brasil (MDS). (2005a). Norma Operacional Básica NOB/SUAS. Recuperado de: http:// www.assistenciasocial.al.gov.br/sala-de-imprensa/arquivos/NOBSUAS.pdf.

Ministério do Desenvolvimento Social e Combate à Fome de Brasil (MDS). (2005b). Política Nacional de Assistência Social PNAS (2004). Brasília, Brasil. Recuperado de https://www.mds.gov.br/webarquivos/publicacao/assistencia social/Normativas/PNAS2004.pdf.

Ministério do Desenvolvimento Social e Combate à Fome de Brasil (MDS). (2006). Norma Operacional Básica de Recursos Humanos do SUAS (NOB-RH/SUAS). Recuperado de: http://www.assistenciasocial.al.gov. br/sala-de-imprensa/arquivos/NOB-RH.pdf.

Ministério de Desenvolvimento Social e Combate à Fome de Brasil (MDS) - Secretaria Nacional de Assistência Social, Centro de Referência Especializado de Assistência Social - CRAS. (2009). Guia de Orientação n ${ }^{\circ} 1$ ( $1^{\text {a }}$ versão). Recuperado de:

http://www.mp.go.gov.br/portalweb/hp/8/docs/guia de orientacao creas. pdf

Ministério do Desenvolvimento Social e Combate à Fome de Brasil (MDS). (2013). Lei n. 8.742, de 07 de dezembro de 1993. Lei Orgânica da Assis- 
tência Social (LOAS) [recurso eletrônico]: Lei no . 8.742, de 7 de dezembro de 1993, que dispõe sobre a organização da Assistência Social e dá outras providências, e legislação correlata. Atualizada em 26/11/2013. Brasília, Brasil: Edições Câmara dos Deputados.

Presidência da República de Brasil. (1979). Lei 6.697 de 10 de outubro de 1979. Código de Menores. Revogada pela Lei 8069 de 1990. Recuperado de: http://www.planalto.gov.br/ccivil 03/leiS/1970-1979/L6697.htm.

Presidência da República de Brasil. (1990). Lei 8.069 de 13 de julho de 1990. Estatuto da criança e do adolescente (ECA). Recuperado de: http://www. planalto.gov.br/ccivil 03/leis/L8069.htm.

Rêgo-Barros, R. (2011). O para todos, o cada um e a política lacaniana. En A. Glaze, F. O. B. Brisset \& M. E. D. Monteiro (Comps.). A saúde para todos não sem a loucura de cada um: perspectivas da psicanálise (pp. 193-198). Rio de Janeiro, Brasil: Wak Editora.

Stevens, A. (2004/1998). Adolescência, sintoma da puberdade. Revista Curinga, 20, 27-39. 